ADTHOR'S ABSTRACT OF THIS PAPER ISBUED BY THE BIBLIOGRAPHIC BERVICE NOVEMBER 10.

\title{
ON THE MORPHOLOGY OF THE RENAL TUBULES OF VERTEBRATES
}

\author{
G. CARL HUBER \\ Department of Anatomy, University of Michigan
}

TWENTY-TWO FIGURES

A comparative study of the renal tubules of the different classes of vertebrates was projected nearly twenty years ago, soon after publishing results of a study on the development and shape of the uriniferous tubules of the higher mammals. ${ }^{1}$ In this study, as projected, it was purposed to reconstruct the excretory tubules of the pronephros and mesonephros of certain of the lower vertebrates, including amphibia, and the metanephric tubules of certain reptiles, birds and mammalia. In the reconstruction, by the Born wax plate method, of the pronephric tubules of a larval toad, and mesonephric tubules of an adult frog and the metanephric tubules of certain reptilia no great difficulty was experienced, and such reconstructions were made, somewhat over fifteen years ago in conjunction with Professor Ward J. MacNeal, sometime Instructor in this department. On attempting to reconstruct the metanephric tubules of birds, it was learned after unsuccessful trials that this was beyond the limits of the method, so also with endeavors to reconstruct the metanephric tubules of adult mammalia. The projected study, therefore, was abandoned for a time. The form of the adult, mammalian renal tubule was later ascertained by specially devised methods of teasing. ${ }^{2}$ This special method of teasing has relatively recently been successfully used in an investigation of the form of the metanephric tubule of birds. I am in a position now, therefore, to present figures giving the morphology

${ }^{1}$ Huber, G. Cari. On the development and shape of uriniferous tubules of certain of the higher mammals. Am. Jour. Anat., Supplement to vol, 4, 1905.

${ }^{2}$ Huber, G. Carl. A method for isolating the renal tubules of mammalia. Anat. Rec., vol. 5, 1911. 
of type forms of renal tubules from the different classes of vertebrates. Their presentation does not seem to me superflous at the present time, even though Zarnik ${ }^{3}$ has in the meantime published an excellent study of the renal tubules of certain reptilia. The duct system of the kidneys of certain of the forms studied does not lend itself readily to investigation by reconstruction methods, owing to magnification necessary to make the requisite drawings, and the size of the resultant model. Therefore, an attempt was made, relatively successful in certain of the forms studied, to ascertain the form of the duct system by means of the celluloid, corrosion injection method devised by me and presented in connection with a study of the arteriolae rectae of the mammalian kidney. ${ }^{4}$ The figures here included, based on preparations collected through many years of work, therefore, are in part of reconstructions made, in part of complete renal tubules isolated by teasing and in part of celluloid, corrosion preparations. It is hoped that the figures will be sufficiently clear to obviate the necessity of extended description. This account is intended more as a pictorial summary of results obtained as concerns the morphology of the renal tubules and the kidney duct systems of certain type vertebrates, than a critical discussion of the minute anatomy of the renal tubules considered, ince the literature is much richer as concerns the latter than that which concerns the morphology of the tubules. Likewise, only the pertinent literature dealing with the morphology of renal tubules is here considered, otherwise this account would be extended far beyond the limits of these pages.

\section{PRONEPHRIC TUBULES}

The reconstruction of the pronephric tubule here figured was ot tained from a series of frontal sections of a larval toad, having a length of $10 \mathrm{~mm}$. The variety of Bufo I am unfortunately unable to give. The ova were collected in a neighboring pond

3 Zarnik, B. Vergleichende Studien über den Bau der Niere von Echinda und der Reptilienniere. Jenaische Zeitschrift, vol. 46, 1910.

${ }^{4}$ Huber, G. Carl. The arteriolae rectae of the mammalian kidney. Am. Jour. Anat., vol. 6, 1907. 
and could not be specifically identified. The reconstruction was made at a magnification of two hundred diameters. The figure is added more with a view of making the series of figures complete than with a view of adding materially to current knowledge of the amphibian pronephric tubule. The figure here given presents similarity to that given by Herbert $\mathrm{H}$. Field, ${ }^{5}$ figure 41, plate 4, a reconstruction of the right pronephros of a larva of Rana having a length of $8 \mathrm{~mm}$., from anterior end to tip of tail. Field's account of the amphibian pronephros is the best available. In the brief statement here given, his nomenclature is used. The pronephric tubule shown in figure 1, pre-

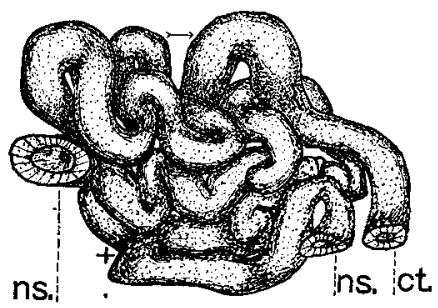

Fig. 1 Reconstruction of the pronephric tubule of a larva of Bufo, the larva having a length of $10 \mathrm{~mm}$. from anterior end to tip of tail. $\times 80$. $n s$, nephrostome; ct., common trunk.

sents only two nephrostomes, ns. The two nephrostomal tubules join in a Y-shaped junction, hidden beneath the model as placed in the figure, in the neighborhood of the region indicated by a cross. The common trunk presents three main loops extending primarily in cephalic caudal direction, each presenting three to four secondary loops. The figure presents a sketch over an enlarged photographic print, the photograph having been taken from a direction which admits tracing the common trunk most completely. The arrow indicates the direction taken by the tubule in the one location where confusion may arise. The actual length of the common trunk reconstructed as measured on the model, is approximately $2.5 \mathrm{~mm}$.

${ }^{5}$ Field, Herbert $\mathrm{H}$. The development of the pronephros and segmental duct in amphibia. Bulletin of the museum of Comparative Zoology at Harvard College, vol. 21, 1891. 


\section{MESONEPHRIC TUBULES}

The mesonephric tubule here figured was reconstructed from the kidney of an adult, female frog, Rana catesbiana. The duct system is figured after corrosion preparations made by injecting through the ductus deferens or ureter, a solution of celluloid in aceton, colored with alkanin. Only now and then was it possible to inject anyway completely the duct system. Usually, owing to the pressure necessary, the ureter ruptures before the desired injection is obtained. After injection, the parts remained in place for fifteen to twenty minutes and were then transferred to a 75 per cent solution of hydrochloric acid, in which they remained for about twenty-four hours. The macerated pieces were then transferred to a large dish of water and the softened tissue removed by playing water against the preparation with a dropper provided with a rubber bulb. After the corrosions were thoroughly cleansed, they were placed in distilled water for a few hours, then dehydrated, and transferred to xylol and if desired mounted in xylol-balsam. The mesonephros-kidneyof the frog is a compound tubular gland, possessing numerous renal or mesonephric tubules, terminating in a series of transverse collecting ducts which unite with the ductus deferens or ureter. The ductus deferens joins the kidney near the posterior end of its dorso-lateral margin, passing forward to the cephalic end, where it becomes partly embedded in kidney substance. Into this main duct there empty at fairly regular intervals and approximately at a right angle numerous transversely coursing collecting ducts, which, with or without branching pass near the dorsal surface of the kidney to near its lateral margin. These transverse collecting ducts have a relatively straight course and are in the main parallel to each other. For the greater part of their course they are embedded in the kidney substance near its dorsal surface. In figure 2, there is presented a corrosion preparation of the ductus deferens with the connected, transversely coursing, collecting ducts from the kidney of Rana catesbiana. The injection in this case was fairly complete and after maceration it was possible to mount in one piece the entire corrosion. 
The transverse collecting ducts are represented for about one half of their entire length. About the full extent of their branching may be observed, since scarcely any branching occurs except relatively near their termination in the ductus deferens. In figure 3 , is shown a corrosion of one of the transverse collecting ducts with the terminal ends of the connected renal tubules, from a region in which the injection extended for a distance into the renal tubules. The transverse collecting tubules shown in figure 3 , corresponds to one of the main side branches of the ductus deferens as seen in figure 2 . The dependent tubules, hooked at the lower end (fig. 3) correspond to that portion of the recon-

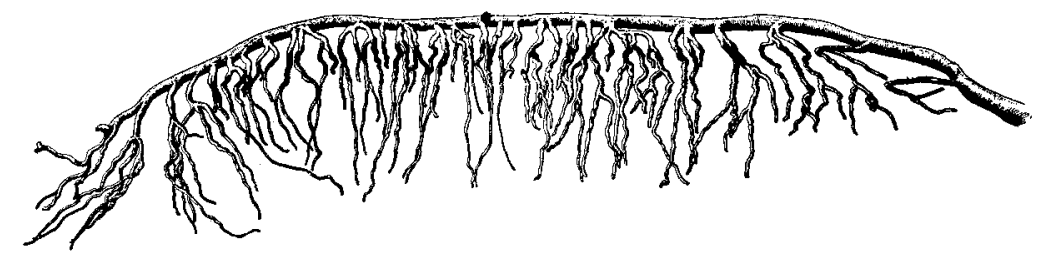

Fig. 2 Corrosion preparation of ductus deferens and transverse collecting tubules of kidney of Rana catesbiana.

structed renal tubule, shown in figure 4, leading to the segment of the reconstructed transverse collecting duct. The manner of termination of the renal tubules in the transverse collecting ducts is clearly shown in figure 3. They end along the ventral border of these collecting ducts in two somewhat irregularly arranged rows. By an imaginary combination of the portions of the duct system of the frog's kidney as detailed in figures 2 and 3 , the entire duct system of the frog's kidney to and including portions of the renal tubules, may be projected.

The renal tubule of the frog-mesonephric tubule-was figured by Nussbaum ${ }^{6}$ many years ago. In figure 28 , plate 23 , Arch. f. Mik. Anat., vol. 27, 1886, he presents a complete uriniferous tubule from the kidney of Rana esculenta, teased after maceration in hydrochloric acid. This figure has been repeatedly

${ }^{6}$ Nussbaum, M. Ueber den Bau und die Thätigkeit der Nierenorgane. Arch. f. Mik. Anat., vol. 27, 1886. 
copied and presents many points of similarity to the figure of a wax reconstruction here shown. In figure 4 , is shown a reconstruction of a complete renal tubule of the frog, Rana catesbiana, beginning with renal corpuscle and ending in the transverse

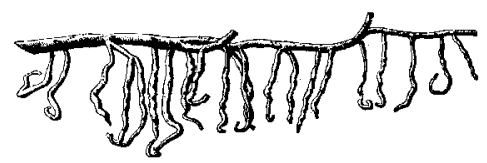

3

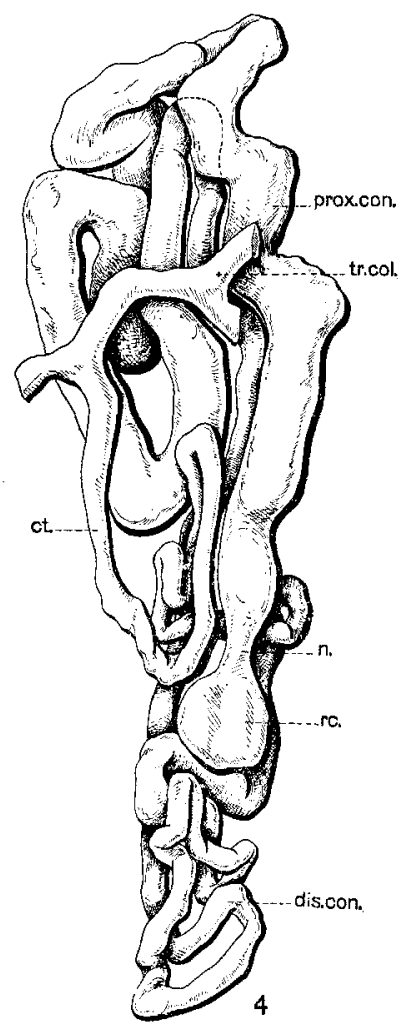

Fig. 3 Corrosion preparation of transverse collecting duct with the terminal portions of the entering renal tubules from the kidney of Rana catesbiana.

Fig. 4 Reconstruction of a renal (mesonephric) tubules of a female frog. Rana catesbiana. $\times 80$. rc., renal corpuscle; $n_{\text {. }}$, neck; prox.con., proximal convoluted segment; dis.con., distal convoluted segment; con.t., connecting tubule; tr.col., transverse collecting duct.

collecting duct. The figure is placed so that the dorsal surface corresponds to the upper border of the figure. A cross section of the kidney of Rana catesbiana appears not unlike figure 64 , 
of Gaupp's7 edition of Ecker's and Wiederscheim's "Anatomie des Frosches," 1905. The renal tubules traverse the entire dorso-ventral thickness of the kidney. The great majority of the renal corpuscles form an irregular layer situated near the ventral surface of the kidney. Each renal tubule begins at a renal corpuscle. The renal corpuscles are relatively large, of flattened oval form, with long axes extending in a dorso-ventral direction. The one reconstructed presents the following measurements: length, $0.125 \mathrm{~mm}$; width, $0.1 \mathrm{~mm}$.; thickness, 0.088 $\mathrm{mm}$. The renal corpuscle is joined to the tubule by a short and narrow neck, n., directed dorsalward, constituting part 1 , of the tubule proper. The neck is lined by relatively short, nonpigmented cells supporting long cilia. The neck is followed by a tubular portion having a relatively large diameter and extending toward the dorsal surface of the kidney there to form several bold loops which may extend to about the middle of the kidney substance. This portion is comparable to what is designated as the proximal convoluted portion of the mammalian renal tubule. Its course is clearly discernible in the figure; I have designated it prox.con., proximal convoluted portion. The actual length of this portion of the tubule reconstructed, as measured on the model, is approximately $3.8 \mathrm{~mm}$., and it has a diameter, on the average, of $75 \mu$. It extends from the narrow neck, just above the renal corpuscle toward the dorsal surface where several bold loops may be observed, then returned toward the ventral surface ending near the level of the renal corpuscle. In the figure this portion of the tubule is partly hidden by the small, coiled tubular portion lying to the left and slightly above the renal corpuscle. The cellular lining of this portion of the tubule is not unlike that lining the proximal convoluted portion of the mammalian kidney, presenting an inner striated border and now and then pigment granules in the basal portions of the cells. The portions of the renal tubules of the frog here designated the proximal corrulated portion, taken collectively, constitute the greater portion of the dorsal half of

${ }^{7}$ Gaupp, E. Ecker's und Wiedersheim's Anatomie des Frosches, Dritte Abtheilung, 1904. Harnorgane, page, 238. 
the kidney substance. This proximal convoluted portion is followed by a short and narrow segment comparable, in position only, to the medullary loop (loop of Henle) of the mammalian renal tubule. In the figure.given, this portion of the tubule reconstructed is practically hidden by the tubular coil complex above referred to. This segment is said to be lined by ciliated epithelium similar to that lining the neck; it constitutes Gaupp's 'Dritter Canalabschnitt.' In the tubule reconstructed this portion presents a length of a little less than $0.2 \mathrm{~mm}$.; however, in the model its delimitation is somewhat uncertain. In the succeeding tubular segment, Gaupp's 'Vierter Canalabschnitt,' the tubule again increases in size slightly, reaching a diameter of about $30 \mu$, and presents numerous coils and loops certain of which reach the ventral surface of the kindey. The general course and relations to the renal corpuscle of these loops is well shown in the figure; they forming the tubular coil complex of the lower third of the figure. This portion presents an actual length of approximately $2.5 \mathrm{~mm}$. It is lined by a short epithelium, presenting basal rodding. In cross sections of the kidney this portion of the tubule is found in the ventral portion, extending from a little above the level of the renal corpuscles to the ventral surface of the kidney. This portion of the frog's renal tubule may be compared to the thicker portion of the ascending limp of the medullary loop and the distal convoluted portion of the mammalian renal tubule and is here designated the distal convoluted portion, dis.con. of figure 4. This segment is succeeded by the final segment leading to the transverse collecting duct. If may be designated the junctional or connecting tubule, con.t., dearly shown in the figure of the model as it joins that segment of the transverse collecting duct, tr.col., reconstructed. In the tubule reconstructed it presents a length of $0.7 \mathrm{~mm}$. In figure 3 , the dependent, hook-shaped tubular portions represent this fifth tubular segment, the junctional or connecting tubule. This portion of the tubule is lined by an epithelium similar to that of the collecting ducts. The entire renal tubule of the frog as reconstructed and presented in figure 4, has a total length of slightly over $7 \mathrm{~mm}$. 


\section{METANEPHRIC TUBULES}

A study of the metanephric tubule requires consideration of the renal tubules of reptilia, birds and mammalia. For this study the renal tubules of a number of species of reptilia were modelled after the Born wax plate method, in the hope that some data concerning the ancestral origin of the metanephric tubule might be obtained. This hope was not realized. There is found a certain resemblance in morphology between the amphibian mesonephric tubule and the reptilian metanephric tubule, but beyond such resemblance in form the kindeys of the types studied present no definite data as to their developmental relationship. Models of renal tubules from kidneys of the turtle, the alligator, the snake and the lizard are here depicted. Zarnik has considered very fully the structure of the reptilian kidney, embracing in his study, among other forms, the kidney of the lizard, the snake the alligator and the turtle. His comprehensive publication appeared after the models here figured were completed, This article is valuable for the literature reviewed as well as for the observations recorded. These as concerns the form of the renal tubules investigated are based almost wholly on teased preparations. My own observations corroborate many of his results. Their publication at this time seems never-the-less warranted in that they are based on models in which, as I have had abundant opportunity to learn, the relations of the different parts of the respective tubules are more accurately maintained than in teased preparations, and further, the forms studied by me are not identical with those investigated by Zarnik. In presenting my own results of the study of the forms of the renal tubules of reptilia it will be necessary from time to time to draw attention to Zarnik's observations, obviating the necessity of a complete review of his work.

For the study of the morphology of the renal tubule of the turtle several such tubules were reconstructed from the kidney

of Chrysemys marginata. The kidney of this turtle presents on its surface shallow grooves, in the main parallel, and having a direction which is in general at right angles with the long axis 
of the kidney. These grooves anastomose here and there. They bound indistinct folds or pseudolobules, drained by main branches of the duct system. The ureter enters on the ventral surface. Two of the several renal tubules reconstructed are reproduced in figure $5, \mathrm{~A}$ and $\mathrm{B}$. In the folds or pseudolobules of the chelonian kidney, as also pointed out by Zarnik, the branches of the renal artery as also the branches of the venae renalis revehentes course through the centers of the pseudolobules, between two layers of kidney substance, which respectively meet in the center
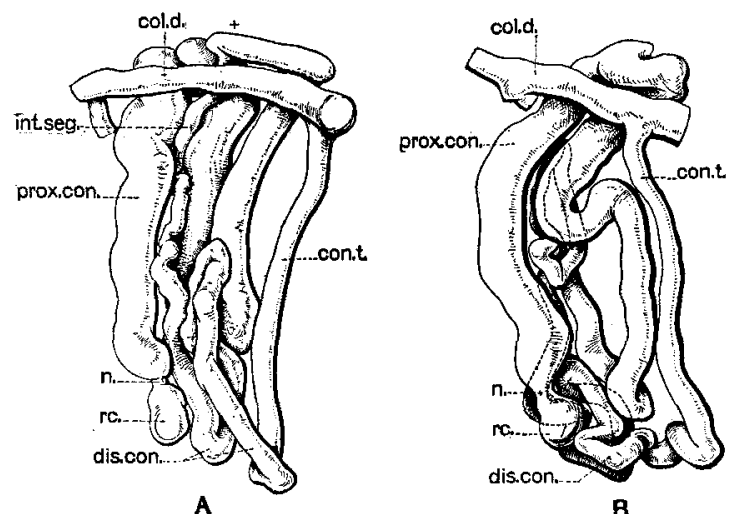

Fig. $5 \mathrm{~A}$ and $\mathrm{B}$, two renal tubules reconstructed from the kidney of Chrysemys marginata. $\times 80, \quad r c$., renal corpuscle; $n$., neck; prox.con., proximal convoluted segment; int.seg., intermediate segment; dis.con., distal convoluted segment; con.t., connecting tubule; col.d., collecting duct.

of the pseudolobules and extend to its surfaces. The main branches of the duct system, arising from the primary branches of the ureter, radiate from the ventral to the dorsal surface of the kidney, coursing in the kidney substance, on each side near the surface of the pseudolobules. Each so called pseudolobule, therefore, is composed of two layers of kidney substance having between them branches of the renal artery and branches of the venae renalis revehentes, each layer being composed of masses or renal tubules, the main axis of whose coil complex is approximately at right angles to the surface of the pseudolobules, and to the main branches of the collecting ducts. 
The renal tubules of Chrysemys marginata begin in a relatively small renal corpuscle averaging about $55 \mu$ in diameter. They are situated on each side near the centers of the pseudolobules forming on each side of the center an irregular layer. The renal corpuscle is followed by a short and narrow neck, lined by an epithelium bearing long cilia. The neck is followed by what may be regarded as the proximal convoluted portion. Zarnik's 'Hauptstück' which courses toward the periphery of the pseudolobule, overlying the associated collecting duct and forms a large and conspicuous portion of the coil complex of each renal tubule. In tubule A, of figure 5, this segment, prox.con. is arranged in the form of a letter $\mathrm{N}$, extending from the neck, $n$., to the region marked by a cross, found at the middle of the upper portion of the figure. The three parts of the $\mathrm{N}$-form present each smaller secondary loops. In tubule $\mathrm{B}$, of figure 5 , the arrangement of the proximal convoluted portion has an arrangement which is essentially the same as in tubule $A$, though the final rising arm of this $\mathrm{N}$-shaped segment is not as long. In tubule $A$, this tubular segment presents a length of $1.5 \mathrm{~mm}$; in tubule $\mathrm{B}, 1.25 \mathrm{~mm}$. and a diameter of from 60 to $65 \mu$. It is lined by an epithelium not unlike that lining the proximal convoluted portion of the mammalian renal tubule, presenting also a striated inner border. Collectively these tubular segments form the outer border of the pseudolobules. This large and long segment is followed by a short and narrow segment, lined by ciliated epithelium and corresponds in position only to the thin arm of the medullary loop of the mammalian renal tubule. In tubule $\mathrm{A}$, of the figure this short intermediate segment int.seg. descends from the region of the cross to the region where the tubule again becomes larger, about the middle of the figure. It has a length of a little less than $0.3 \mathrm{~mm}$., and a diameter which averages $20 \mu$. In tubule $B$, this segment is represented by the dotted loop found a little to the left of the middle of the figure. 'This intermediate segment is followed by what I shall designate as the distal convoluted portion, forming in both tubules figured a dense coil complex in the region of the renal corpuscles, thus found near the center of the pseudolobules. In both tubules 
this segment presents a length of very nearly $1 \mathrm{~mm}$., and a diameter which varies from $30 \mu$ to $45 \mu$. This segment is lined by a low columnar epithelium showing a striated protoplasms. It is followed by a junctional or connecting tubule, con.t., which in both figures lies to the right, extending respectively from t_e loop which lies at the lower right hand corner of each tubule figured to the segment of the collecting duct which crosses each tubular complex at approximately a right angle, col.d. This tubular segment has a length of $0.5 \mathrm{~mm}$. This gives a length to tubule $A$, from renal corpuscle to collecting duct of $3.3 \mathrm{~mm}$. The tubules here figured are similar to those figured by Zarnick, both in form and arrangement, except that the duct segment
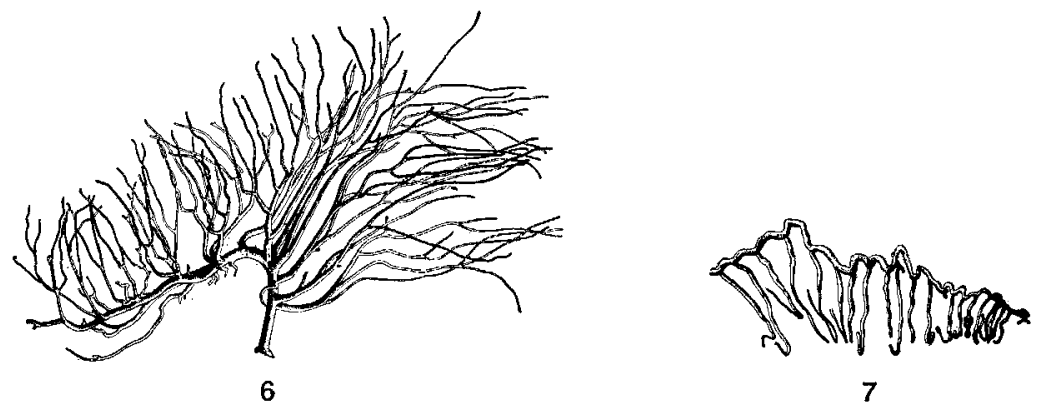

Fig. 6 Duct system of pseudolobule of kidney of Chrysemys marginata, corrosion preparation.

Fig. 7 Distal collecting duct with connecting or junctional tubular segments of renal tubules emptying therein, Chrysemys marginata, corrosion preparation.

figured by him crosses the coil complex a little nearer its center than in my figures, see Zarnik's figures 35 to 37 of plate 7 . Other renal tubules modelled from the kidney of Chrysemys marginata and not here figured are in their morphology not unlike the tubules here figured.

In figure 6 is represented a drawing of a fairly complete celluloid corrosion injection of the duct system of a pseudolobule. The main duct, bottom of the figure, arises from the ureter on the ventral surface of the kidney. The primary and secondary branches radiate toward the dorsal surface of the respective pseudolobules, coursing in the kidney substance, on each side 
nearer the surface of the pseudolobule than its center. Into each of the branches empty numerous renal tubules. In figure 7, is shown one of the radiating collecting ducts, many of which are figured in figure 6, taken from a corrosion injection in which the injection mass in certain parts extended for a distance into the connected renal tubules. In this figure, each dependent, hook-shaped tubule corresponds to a connecting or junctional tubule as figured in the reconstructions shown in $\mathrm{A}$ and $\mathrm{B}$ of figure 5. The segment of the collecting duct shown in figure 5, col.d. corresponds to a short segment of the distal collecting duct uniting the several connecting tubules as seen in figure 7 , or of the radiating and branching ducts depicted in figure 6 . Figures 6 and 7 , give a better perspective of the duct system of the chelonian kidney than do figures 41 and 42 of plate 7 of Zarnik's contribution.

Alligator. For the material used in the study of the renal tubule and collecting ducts of kidney of the alligator, I am indebted to Doctor Greenman, Director of the Wistar Institute, who kindly furnished me several specimens of Alligator mississippiensis, measuring approximately two feet in length. All previous descriptions of the kidney of the alligator note its simple structure. It is found accurately described by Zarnik in his comprehensive contribution in which he discusses and in many points corroborates the earlier observations of Solger ${ }^{8}$ and Szakall. ${ }^{9}$ In the kidney of the alligator the ureter divides near the caudal end of the kidney into a dorsal and ventral branch which course respectively along the dorsal and ventral surface of the kidney. Into these two branches of the ureter empty numerous lateral, primary collecting ducts, which after division extend on each side of the ureter to near the lateral and median borders. In figure 8 , is represented the cephalic end of the ventral ureter with the primary collecting ducts termination

${ }^{8}$ Solger, B. Zur Kenntnis der Krokodilniere und der Nierenfarbstoffe niederer Wirbeltiere. Zeitsehr. f. wiss. Zool., vol. 41, 1885.

Szakall, T. Über den Bau des Urogenitalsystems des Krokodils. Inaug.Diss. Giesen, 1899. Seen by me only in review (Page, 311, Herwtig's Handbuch der Vergleich. u. Experiment. Entwicklungslehre, Dritter Band, Erster Theil, 1906. 
therein, as obtained from a preparation made by the celluloid injection corrosion method. In the lower left of the figure is indicated the manner of termination of the initial collection duct coming from the renal tubules. In figure 9 is given a drawing of a very completely injected corrosion preparation of one of the side branches of the ureter with the connected initial collecting ducts. These terminate in the respective collecting ducts in two fairly regular rows as is evident from the figure. A comparison of figures 8 and 9 of this article with figures 33 and 34 , plate 6 , of Zarnik's contribution will show a close correspondence of results obtained by methods of teasing and corrosion injection
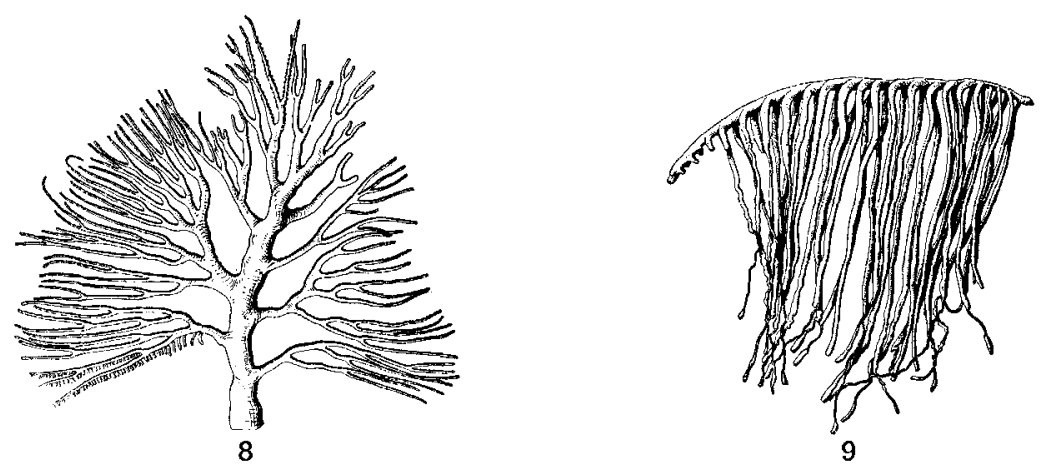

Fig. 8 Cephalic end of ventral branch of the ureter, with lateral branches, collecting ducts, alligator mississippiensis, corrosion preparation.

Fig. 9 Lateral collecting duct, receiving the distal ends of the renal tubules terminating therein, connecting tubules, alligator mississippiensis, corrosion preparation.

as concerns the duct system of the alligator kidney. The substance of the alligator's kidney is arranged in a dorsal and a ventral half, corresponding to the dorsal and ventral branches of the ureter, separated by. a small amount of connective tissue and branches of the renal artery and accompanying veins. The dorsal and ventral portion of the renal substance are minor pictures, so far as tubular arrangements and ducts are concerned. This is clearly shown in text-figure 34 and figure 52, plate 10 of Zarnik's article and this is confirmed in my own serial sections. This observer successfully teased the renal tubules of the alli- 
gator as may be seen from his figure $30 \mathrm{a}$, plate 6 . In figures $\mathrm{A}$ and $\mathrm{B}$, of figure 10 , are reproduced two renal tubules of alligator mississippiensis reconstructed after the Born method. They are taken from the thicker central and slightly thinner lateral portions of a series of cross-sections. The renal corpuscles of the

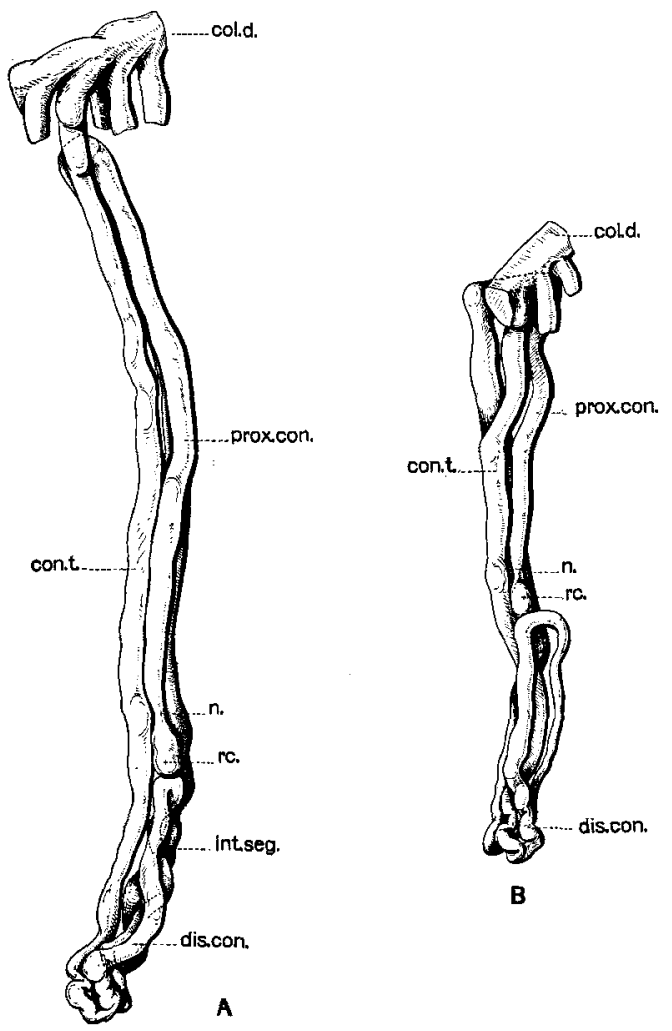

Fig. 10 A and B, reconstructions of two renal tubules of alligator mississippiensis. $\times 80$. $\quad r c$., renal corpuscle; $n$., neck; prox.con., proximal convoluted segment; int.seg., intermediate segment; dis.con., distal convoluted segment; con.t., connecting tubule; col.d., collecting duct.

several tubules form a fairly regular layer in each half of the kidney substance, a little distance away from the connective tissue septum. The renal corpuscle forming the beginning of the tubule A, figure 10 , presents a flattened oval form with a cross diameter of $45 \mu$. The renal corpuscle is followed by a narrow 
neck, directed toward the periphery, which in the alligator is not lined by ciliated epithelium. The neck is followed by a long, slender loop, which extends from the renal corpuscle to the pheriphery of the kidney, looping back again to about the level of the renal corpuscle. This loop, which is very simple in arrangement, forms the proximal convoluted portion, prox.con., and is lined by an epithelium having a striated inner border. Its length in this tubule is $2.3 \mathrm{~mm}$. and it presents an average diameter of a little over $40 \mu$. This segment is followed by a short intermediate segment, lined by ciliated epithelium, extending from about the level of the renal corpuscle to the loop coil shown at the lower end of the figure. In the model, this portion is not clearly demarked; it presents a length of about $0.3 \mathrm{~mm}$. This portion is followed by the distal convoluted portion, forming the coil complex with the short ascending loop, forming the lower end of the figure, and leading to the long connecting tubule and initial collecting duct ascending, quite free, at the left the of figure. The distal convoluted portion presents a length of $0.8 \mathrm{~mm}$. and the connecting tubule and initial collecting duct, together, a length of $1.1 \mathrm{~mm}$., making the entire length of this tubule $4.5 \mathrm{~mm}$. Tubule $\mathrm{B}$, of figure 10 , is very similar in form and arrangement of parts to tubule $A$, differing from it only in being slightly shorter.

Snake. For the investigation of the snake's kidney, the common stripped snake, Eutaenia sirtalis Baird, was chosen. Zarnik reports on the renal tubules of a number of ophidian forms, basing his study on teased preparations. The left kidney was studied; the duct system by the corrosion injection method, the renal tubules by means of wax reconstruction. In the stripped snake the left kidney is an elongated, slightly lobulated organ, the ureter coursing along the ventral and ventro-menial border to near its cephalic end. In figure 11, is shown a corrosion of the ureter with the attached primary collecting ducts. These, as may be seen from the figure, enter the ureter at a very acute angle and after a short distance turn at nearly a right angle, to course over the dorso-lateral surface of the kidney; receiving the initial collecting ducts. In figure 12, is presented one of the 
main side branches of the collecting duct system, taken from a very fully injected preparation, in which the injection mass extended into the initial collecting ducts. Their manner of terminating in the superficially placed collecting ducts is clearly shown in the figure. In figure $A$, and $B$, of figure 13 , are presented two views of a modle of a renal tubule of the common, stripped snake. In $\mathrm{B}$, the reconstruction as viewed from the side as shown in $A$, is presented as when viewed from the convex side. The renal tubules of the snake, at least in the form studied,

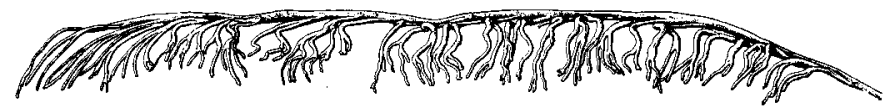

Fig. 11 Ureter with collecting ducts terminating therein from the leit kidney of the common stripped snake, Eutaenia sirtalis; corrosion preparation.

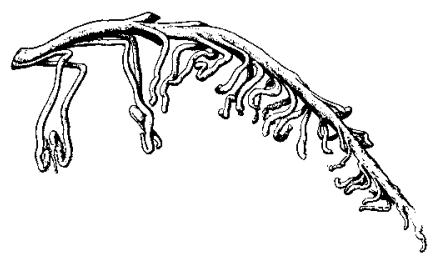

Fig. 12 Collecting duct of the kidney of Eutaenia sirtalis, the common stripped snake, with the distal ends of renal tubules emptying therein, corrosion preparation.

present an arched form as seen in figure 13, A, and a quite compact arrangement, somewhat difficult to portray in a figure. In this renal tubule, the renal corpuscle is relatively small and of nearly spherical form, having a diameter of $43 \mu$. This is attached to a long slender neck, lined by ciliated epithelium, which is followed by the proximal convoluted portion, arranged in the form of a main loop extending from the renal corpuscle to the region of the surface collecting ducts and returning again to a little below the level of the renal corpuscle. This main loop, which presents a number of secondary loops, has a length if $1.6 \mathrm{~mm}$. and is lined by an epithelium having a striated inner border. The proximal convoluted segment is followed by a 
short intermediate portion lined by ciliated epithelium and this in turn by the distal convoluted portion. This later portion forms the coil complex well seen at the bottom in B, of figure 13, forming in reality a long loop, direeted away from the collecting duct, toward which it returns and with which it connects through a long slender connecting tubule and initial collecting duct. The
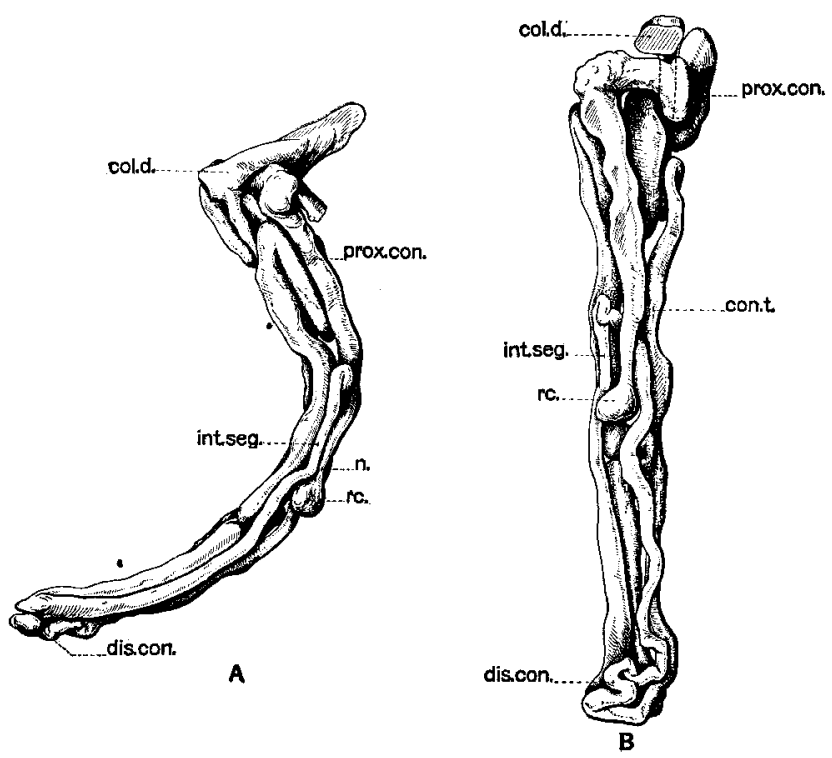

Fig. 13 A and B. Two views of the same renal tubule retonstructed from the kidney of the snake, Eutaenia sirtalis. $\times 80$. Figure A, gives a sideview, figure $\mathrm{B}$, the same model as viewed with the convex side toward the observer. $r c$., renal corpuscle; n., neck; prox.con., proximal convoluted segment; int.seg., intermediate segment; dis.con., distal convoluted segment; con.t., connecting tubule; col.d., collecting duct.

distal convoluted portion has a length of $1.5 \mathrm{~mm}$. and the connecting tubule a length of $0.75 \mathrm{~mm}$., giving the entire tubule a length of $4 \mathrm{~mm}$. The figures here given showing a reconstruction of the ophidian renal tubule bears a close resemblance to figures 24 and 25, of plate 5, of Zarnik's article.

Lizard. The limited material at my disposal did not enable me to attempt a study of the duct system of the lizard's kidney 
by means of corrosion injection methods. Several renal tubules were reconstructed from a series of cross sections of a kidney of a small lizard which unfortunately was not specifically identified. The single figure here given, figure 14, is added more for confirmation of the results of a much more complete study, by means of teasing, of the kidney of the lizard by Zarnik. As may be observed from a study of figure 14, the renal corpuscle is of nearly spherical form having a diameter of $55 \mu$. The neck is short and is lined by ciliated epithelium. The proximal convoluted portion, Zarnik's 'Hauptstück,' forms a long N-shaped, double loop, with numerous secondary loops, having a length of $1 \mathrm{~mm}$. This tubular segment is lined by relatively clear epithelium

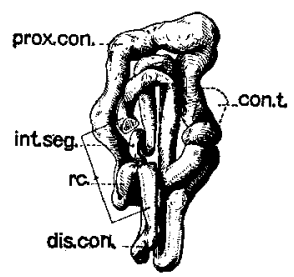

Fig. 14 Reconstruction of renal tubule of the lizard. $\times 80$. rc., renal corpuscle; prox.con., proximal convoluted segment; int.seg., intermediate segment; dis.con., distal convoluted segment; con.t., connecting tubule.

having an inner striated border. Its relation to the renal corpuscle is not unlike that found in the mammalian renal tubule. The intermediate segment, 'Übergangsstück' and 'Schleifenstück' of Zarnik's is lined by ciliated epithelium and forms a short segment, in close relation with the renal corpuscle. This is followed by the distal convoluted portion, consisting of a U-shaped loop with numerous secondary loops, having a length of $0.6 \mathrm{~mm}$. This segment joins the collecting duct by means of a short and relatively thick connecting tubule. The entire length of the tubule figured is a little less than $2 \mathrm{~mm}$. The different parts of the tubule are compactly arranged, forming a coil complex more closely grouped than in the renal tubules of the other reptilian forms studied by me. Figure 14, of this article should be compared with figure 12a, plate 3, of Zarnik's contribution, both figures are very similar in all essentials. 


\section{AVIAN METANEPHRIC TUBULES}

For the study of the metanephric tubule of birds I made use of the kidneys of adult roosters, Gallus domestica. As stated in the introduction to this article an attempt was made quite a number of years ago to reconstruct by means of the wax plate method, the renal tubules of birds, using for this work, series of cross sections of the kidney of the dove. After a number of attempts and the consumption of much time this method was abandoned since success did not seem attainable. It is only relatively recently that time and opportunity presented itself to again take up the investigation of the avian renal tubule, this time by methods of maceration and teasing. This latter attempt has proven more successful. The material was prepared for teasing by injecting under about 20 pounds of pressure, the fresh kidney, through the renal artery with a 75 per cent solution of hydrochloric acid. After this injection, the kidneys was removed and placed in a solution of hydrochloric acid of like strength for a period of several hours, then thoroughly washed in water, stained in an alum hematoxylin solution and teased under the steroscopic binocular.

While the isolation of complete renal tubules from the bird's kidney presents less difficulty than the isolation of complete renal tubules from the mammalian kidney, still it requires hours and hours of teasing and the passing over of many failures before one obtains a series of satisfactory preparations. The literature contains few references and fewer figures relating to the renal tubules of birds. One very brief reference is found in Chapter 21, Stricker's Manual of Histology (English translation, Wood and Co., New York, '72) written by Carl Ludwig. In figure $171 \mathrm{D}$ of this text is presented a diagrammatic outline drawing representing a renal tubule from the kidney of a dove. A footnote states that this figure was designed by Hüfner. The text contains the following reference to this figure:

It will be noticed at once how strong the resemblance is to the uriniferous tubule of Mammals. The several subdivisions which we make in the latter are also to be found here, and they occur in the same order. As far as our present knowledge goes, the uriniferous tubules of all birds are made on the same plan as those of the dove. 
The kidney of the bird is an elongated, distinctly, lobulated organ, with the ureter on the ventral and mesoventral side. Prominent branches pass from the ureter to the several lobules. The ventral or mesoventral portion of each lobule presents a short renal pyramid. The central core of a lobule presents an appearance which is not unlike that presented by the mammalian kidney, namely, a shallow medulla and a cortex. The cortex, particularly, extends on all sides beyond the limits of this central core, presenting an appearance not unlike that presented by the reptilian kidney, especially the chelonian kidney. It is perhaps fortunate for this work that it was necessary to resort to methods of teasing by reason of failure with the method of reconstruction in that the teasing method admits of taking tissue portions from all parts of a lobule, while with reconstruction methods one is limited, by reason of consumption of time, to a reconstruction of one or a small number of tubules. In this study it was early evident that the renal tubules forming the periphery of the lobules presented a form which is very much simpler than is presented by those forming the central core of the lobules. The former presenting a form and arrangement of parts which is not unlike that of the reptilian renal tubules, while the latter present a form and arrangement of parts which resemble the mammalian renal tubules, with transition from one type of tubule to the other in an intermediate zone. From the many renal tubules of birds, successfully and completely isolated, and permanently mounted, I have selected a small series showing this transition from the reptilian type of tubule to the mammalian type. The necessary drawings were made from permanently mounted, completely isolated renal tubules, at a magnification of 200 , by aid of camera lucida. In order to bring the figures to a size making reproductions as text figures possible, and yet maintain the same magnification for all the figures of renal tubules of birds, the figures here given represent just half the magnification of the figures detailing the amphibian and reptilian renal tubules. The measurements given for the renal tubules of birds are taken from the drawings, and are perhaps not as accurate as those taken from wax reconstructions. 
They give, however, very nearly the actual lengths of the respective renal tubules. In considering the diameter of the different parts of the renal tubules of birds, as here figured, it should be understood that in order to mount permanently in glycerine the completely teased renal tubules it is necessary to allow them to dry partially on the slide after the removal of the fluid in which they are teased. This fixes them to the slide sufficiently so that they are not broken and distorted when the cover glass and mounting fluid are added. However, in this process the respective tubule loses in diameter, though scarcely in length. The camera lucida drawing here reproduced, therefore, do not represent the full diameter of the tubules figured. It is further to be understood that in order to be certain that the tubule under teasing is in reality a single tubule, it is necessary to tease and separate all coils or loops and to be able to tease completely from renal corpuscle to collecting ducts the entire tubule. This makes it difficult and quite impossible to bring the several parts into normal positions, though there is a marked tendency for a given tubule to do this if allowed to remain undisturbed for a few moments in the fluid in which it is being teased. However, the manipulations necessary to mounting permanently such a preparation usually leads to slight distortion and movement of parts so that the respective tubule comes to rest on the slide slightly spread out, admitting usually of readier interpretation and clearer representation in drawing, but does not present the normal relations of parts. In this latter respect tubules isolated by teasing suffer in comparison with such as are reproduced by wax reconstruction.

It is my purpose to discuss the several types of renal tubules of the bird observed, by beginning with a consideration of the simplest type and proceeding to the larger and more complex types. In figure 15, A, B and $\mathrm{C}$, are reproduced three renal tubules taken from the more peripheral portions of one of the lobules of the kidney of an adult rooster. Each is complete from renal corpuscle to collecting duct. A comparison of these figures with the figures here given of the reptilian renal tubule, especially $\mathrm{A}$ and $\mathrm{B}$, of figure 5 , will show that there exists a 
marked morphologic similarity in form and arrangement of parts of the reptilian and certain avian renal tubules. In each of the three tubules reproduced in figure 15 , the renal corpuscle is relatively small and of nearly spherical form. Each is joined to the respective tubule by a narrow neck. This is followed by a tubular segment which constitutes the proximal convoluted portion, arranged in each of the three tubules figured in the form of a letter $\mathrm{N}$, each part of the $\mathrm{N}$ presenting numerous secondary

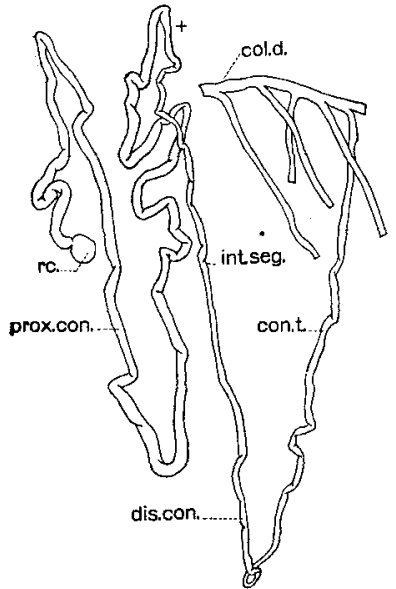

A

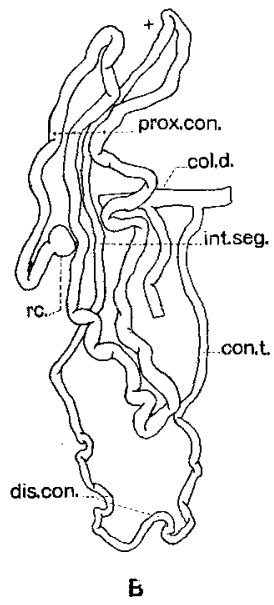

B

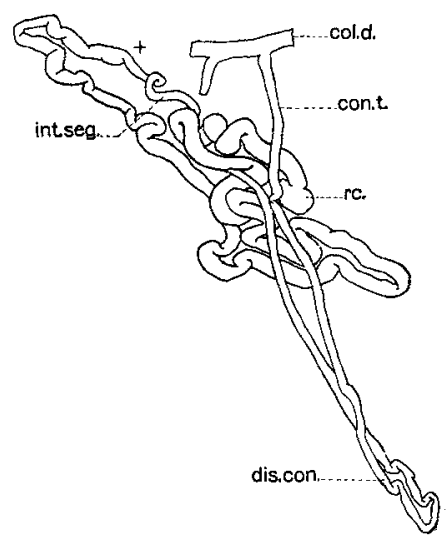

C

Fig. 15 A, B and C. Three renal tubules of the reptilian type, teased from the peripheral protion of a renal lobule, from the kidney of an adult rooster, Gallus domistica. $\times 40$. rc., renal corpuscle; n., neck; prox.con., proximal convoluted segment; int.seg., intermediate segment; dis.con., distal convoluted segment; con.t., connecting or junctional tubule; col.d., collecting duct.

loops, all partly extended in the preparations as mounted. The arrangements of the tubular segment is perhaps most clearly shown in tubule $\mathrm{A}$, in which its general course is clearly followed. A study of tubule $B$, shows the same arrangement and in tubule $\mathrm{C}$, the greater part of the coil complex, tilted accidently to the left, constitutes this tubular segment. In this part of tubule $\mathrm{C}$, the normal relation of the respective loops is better maintained than in the other two tubules. If the coil complex in C, tilted diagonally to the left, be brought in line with the rest of the 
figure, fairly normal relations are obtained for all of this tubule. The actual length of the proximal convoluted tubular segment in the three tubules shown in figure 5 , is $-\mathrm{A}, 3.8 \mathrm{~mm}$.; $\mathrm{B}-3.5$ $\mathrm{mm} . ; \mathrm{C}-3.6 \mathrm{~mm}$. I realize fully that there exist several sources of error in the method used in obtaining the actual length of the several tubular segments considererd--measuring the tubule as drawn enlarged in the figure and dividing by magnification usedhowever, the length given may be regarded as approximately correct. Macerated and teased preparations, even where mounted in glycerine, present very little evidence as concerns the cellular structure of the different segments, a slight difference in the depths of staining may be observed, but the nuclei are not differentiated. In this respect the method of teasing is less favorable than wax plate reconstruction, since in the latter a very complete series of sections is a necessity. However, the proximal convoluted portion of the birds renal tubule is readily recognized and presents a structure which is similar to that shown for this tubular segment of the mammalian renal tubule. In the three renal tubules presented in figure 15, the proximal convoluted segments of each tubule terminate at the upper limits of the figure, at the region indicated by a small cross. This tubular segment is followed by a relatively thin tubular portion, comparable to the thin arm of the medullary loop of the mammalian renal tubule, though its epithelium is not of a distinctly squamous type. This segment, which may be known as the intermediate segment, in the majority of the tubules completely or only partially teased presents a number of small loops, difficult to unravel. This intermediate segment is followed by the distal convoluted portion, consisting of a number of compactly arranged loops and coils, also forming a portion difficult to tease. In the three tubules figured this portion is presented as unroled and forms the most dependent part of each of the three figures. By means of the connecting or junctional tubular segments, the distal convoluted portions join the respective collecting ducts; the distal end of the collecting ducts in the peripheral portions of the lobule, coursing nearly parallel to the dorsal surface of the lobule and receiving connecting tubules 
at short intervals. This may in part be seen in A, of figure 15, in which a short segment of a terminal collecting duct, receiving four connecting or junctional tubules is shown. The entire length of tubule A, figure 15, as measured from the drawing is $6.5 \mathrm{~mm}$. In figure 16 is reproduced a drawing of a tubule completely isolated from a small portion of tissue taken from the periphery of one of the lobules. The parts indicated for the tubules described under figure 15 are present in this tubule, though it was found as a much more compact mass before teasing, and is mounted spread out in nearly a single plane. The entire length of this tubule is approximately $8 \mathrm{~mm}$., of which $4 \mathrm{~mm}$. falls

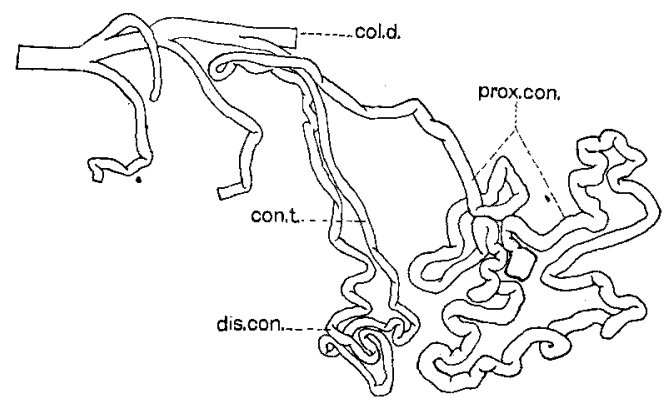

Fig. 16 Renal tubule from bird, Gallus domestica, teased from the peripheral portion of a renal lobule. $\times 40$. The proximal convoluted segment, prox.con., and the distal convoluted sgement, dis.con., are here clearly represented.

to the proximal convoluted portion. In the figure of this tubule, the two coils complexes constituting the proximal and distal convoluted segments, are clearly seen in the two distinct groups of loops forming the right and left part of the figure. In figure 17 , is presented a drawing of a completely isolated tubule with a portion of the connected duct system, taken from the more peripheral portion of the central part of a lobule. This tubule approaches in form and arrangement of parts a mammalian renal tubule, having a short medullary loop which presents, however, a number of small secondary loops. The renal corpuscle is of sperical form and is relatively larger than in the tubules shown in figures 15 and 16. The initial portion of the 
proximal convoluted segment extends toward the ventral portion of the lobule toward the region of the medulla, then returns toward the periphery of the cortex to form an extended loop with many secondary, smaller loops. The length of this proximal convoluted segment, which forms the coil complex at the left, of the figure and extends from the renal corpuscle to the region

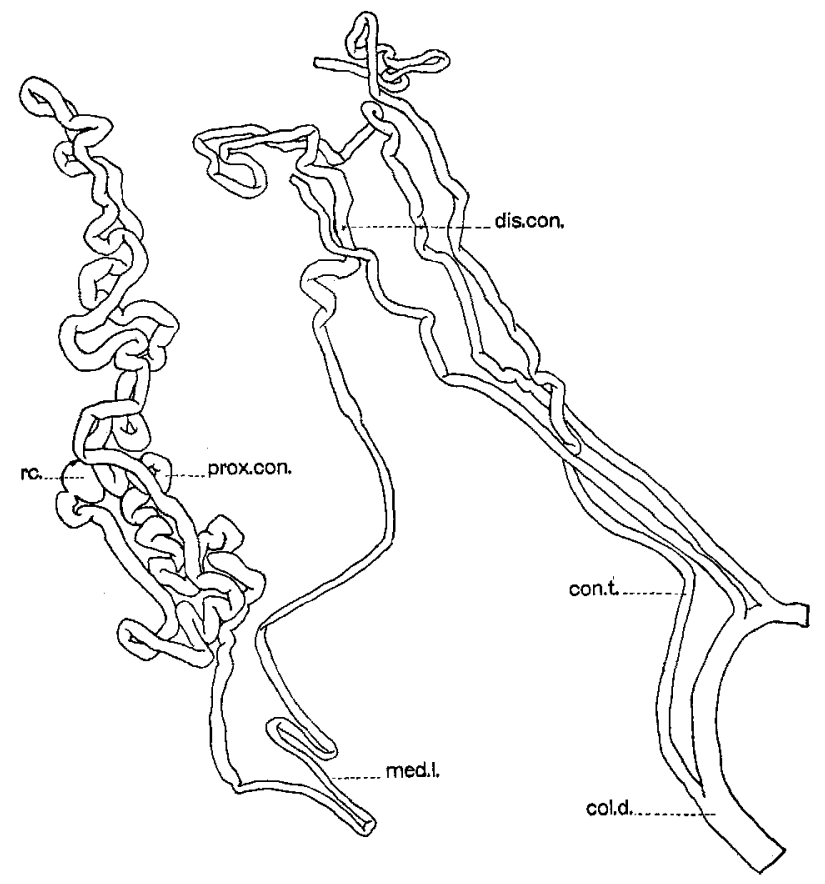

Fig. 17 Renal tubule of the bird, Gallus domestica, completely isolated by teasing, showing transition from reptilian to mammalian type or renal tubule. $\times 40$. $r c$., renal corpuscle; prox.con., proximal convoluted segment; med.l., medullary loop; dis.con., distal convoluted segment; con.t., connecting tubule; col.d., collecting du'et.

where the tubule becomes suddenly thinner, is approximately $7.5 \mathrm{~mm}$. ; thus approaching the length of the proximal convoluted segment of the mammalian renal tubule. The medullary loop of this tubule is relatively short, having a length of $1.8 \mathrm{~mm}$. and ending in the region where the tubule again increases in size; about the middle of the figure. This segment is followed by a 
second coil complex, forming the distal convoluted portion, practically unrolled as presented in this figure, in reality forming a compact coil complex, and leading to. a relatively long connecting or junctional tubule ending in the collecting duct. The entire length of this tubule is approximately $13 \mathrm{~mm}$. In figure

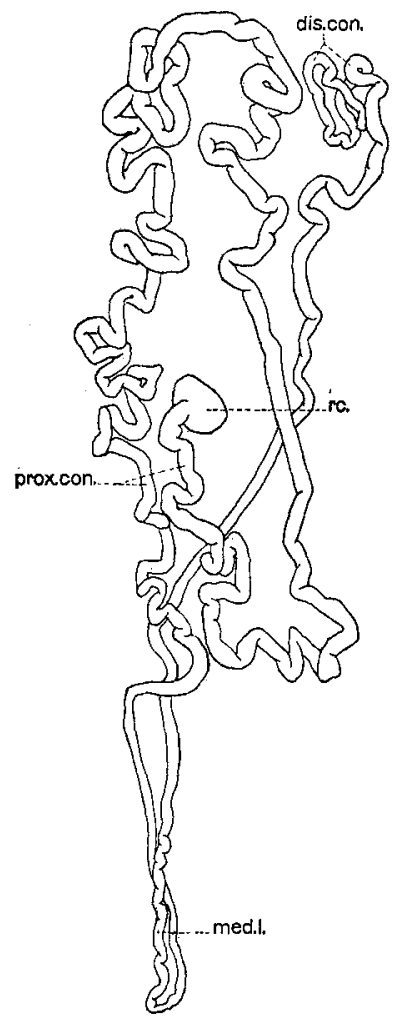

Fig. 18 Renal tubule of the bird, Gallus domestica, isolated by teasing. $\times 40$. This renal tubule possesses a short medullary loop, presenting short loops in the distal arm. The different segments are so placed as to be easily recognized. Figure legends as for figure 17.

18 is reproduced a tubule which was very successfully mounted with reference to exposing the several segments of the tubule, which is very similar to that shown in figure 17 , though it was broken in teasing just distal to the distal convoluted portion, so that its relation to the collecting duct cannot be shown. The 
relatively large renal corpuscle of spherical form, the long proximal convoluted segment, arranged in the form of a long loop with numerous secondary loops, the short medullary loop and the distal convoluted portion, are clearly seen in this figure. This tubule, to the extent contained in the figure, has a length of $13.5 \mathrm{~mm}$., to which perhaps $1 \mathrm{~mm}$. need be added to complete the length to the collecting duct. Of this length, $8 \mathrm{~mm}$. falls to the proximal convoluted portion. Tubules very similar in form and relation of parts to those reproduced in figures 17 and 18 may be found in the peripheral cortical portion of the mammalian kidney, especially in the human kidney, in which tubules are found which do not pass the limits of the cortex.

In figure 19, is reproduced a camera lucida drawing of a renal tubule from the bird, taken from the central portion of one of the kidney lobules. This preparation was very successfully teased and is permanently mounted just as shown in the figure, in which the several segments are so placed that their course may be followed with ease. This renal tubule of the bird is representive of the type of avian renal tubules, which in general form, sequence and relation of parts, relation to cortex and medulla is in essentials very similar to a mammalian renal tubule. The figure seems to me so clear that lengthy discussion is unncessary. The relatively large renal corpuscle, of spherical form, joins the proximal convoluted portion by means of a short neck. The proximal convoluted portion is arranged in the form of a long loop, with numerous secondary loops, extending toward the periphery of the cortex and returning to the vicinity of the renal corpuscle and for a distance into the medulla. The length of this tubular segment, from renal corpuscle to the region of the small cross, is approximately $8.5 \mathrm{~mm}$. The medullary loop (loop of Henle) extends for a distance into the medulla. In the teased preparation it was not possible to determine definitely the character of its epithelium, though the proximal arm appears stained slightly lighter than the distal arm as though lined by a thinner epithelium. The distal arm returns toward the cortex and comes in close relation with the renal corpuscle of the tubule, this relation is not shown in the mounted preparation but was 


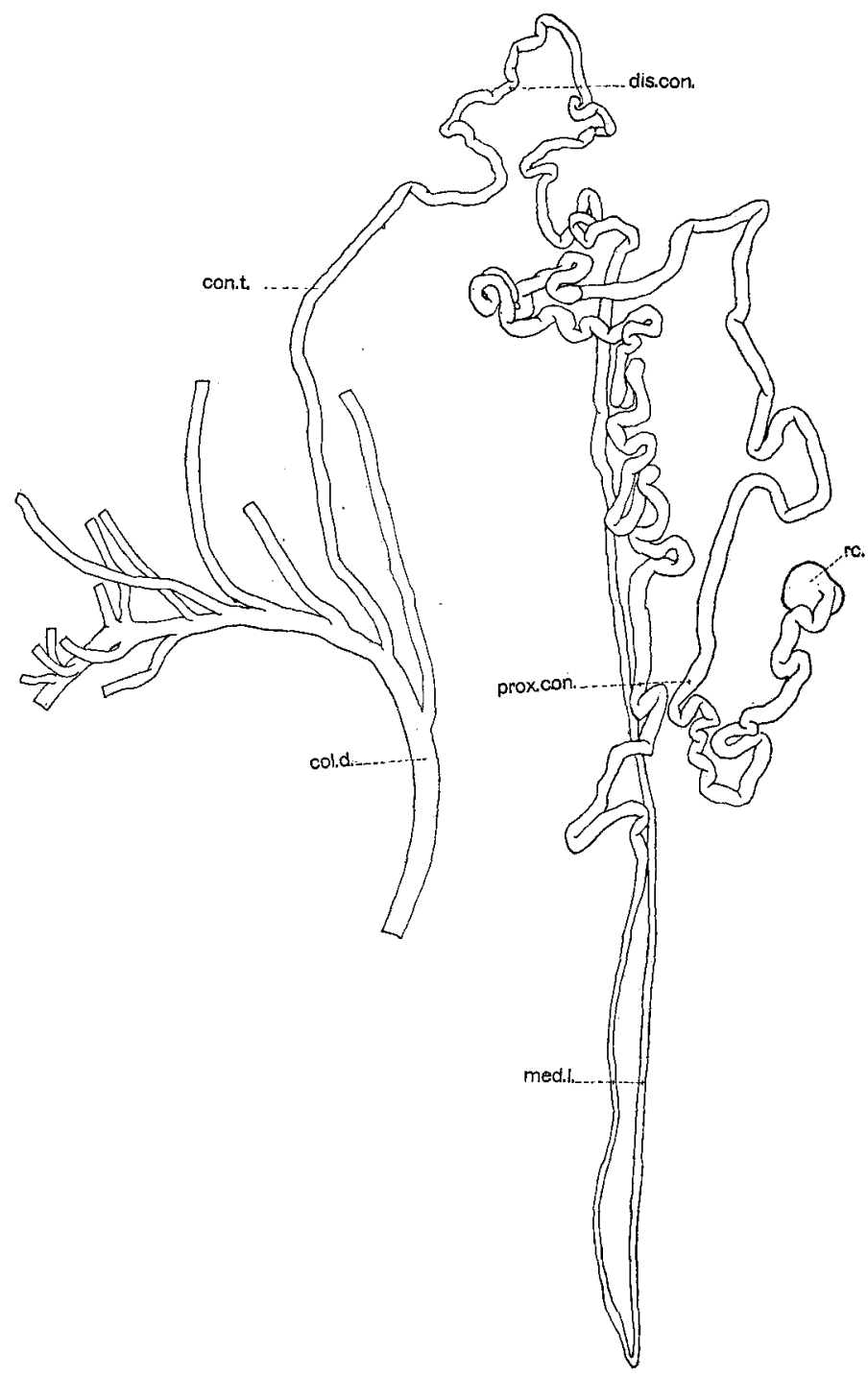

Fig. 19 Renal tubule of bird, Gallus domestica, isolated by teasing from the central portion of a renal lobule. $\times 40$. This tubule is of the mammalian type of avian renal tubules. rc., renal corpuscle; prox.con., proximal convoluted segment; med.l., medullary loop; dis.con., distal convoluted segment; con.t., connecting or junctional tubule; col.d., collecting duct. 
ascertained before the tubule was completely teased. The length of the medullary loop with the ascending limb to beginning of distal convoluted portion (coil complex, upper right of figure) is $3.6 \mathrm{~mm}$. The distal convoluted portion, upper right of figure, presents two more prominent loops each with several secondary loops. Before teasing, this portion was compactly arranged and has a length of $2.2 \mathrm{~mm}$. It is followed by a long connecting or junctional tubular segment leading to the collecting duct, and adding $1.2 \mathrm{~mm}$. to the length of the tube. As may be seen from the figure a portion of the collecting duct system was isolated in connection with the tubule figured. The branches of the collecting duct figured represent other renal tubules connecting with the same. The entire length of this tubule is approximately $15.5 \mathrm{~mm}$, as measured from the drawing. In figure 20, is reproduced a camera lucida drawing of the longest renal tubule of the bird isolated. It comes from the central portion of a renal lobule. In trying to mount permanently this preparation, I endeavored to adjust slightly the position of the renal corpuscle, with the result that the renal tubule was broken in two places in the immediate vacinity of the renal corpuscle. The broken pieces, represented by dotted lines, were brought to place as shown in the figure. This tubule is not so favorably placed in the permanent mount as the one shown in the previous figure. However, it is thought that the different parts can be traced. The tubule shown in figure 20, presents the following measurements-proximal convoluted portion, $7.5 \mathrm{~mm}$.; medullary loop with distal ascending limb to beginning of distal convoluted portion- $6.5 \mathrm{~mm}$; d distal convoluted segment-2.2 mm.; connecting or junctional segment-2 mm.; giving the entire tubule from renal corpuscle to collecting duct a length of $18.2 \mathrm{~mm}$., which is somewhat over half the length of the longest mammalian renal tubule isolated by me. In figure 21 , is shown a camera lucida drawing taken from the most

Fig. 20 Renal tubule of the bird, Gallus domestica. Mammalian type of avian renal tubules; isolated by teasing. Tubule was broken in making permanent mount; broken parts outlined in dotted lines. $\times 40$. Figure legends as in figure 19. 


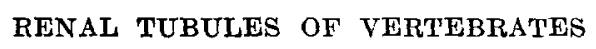

335

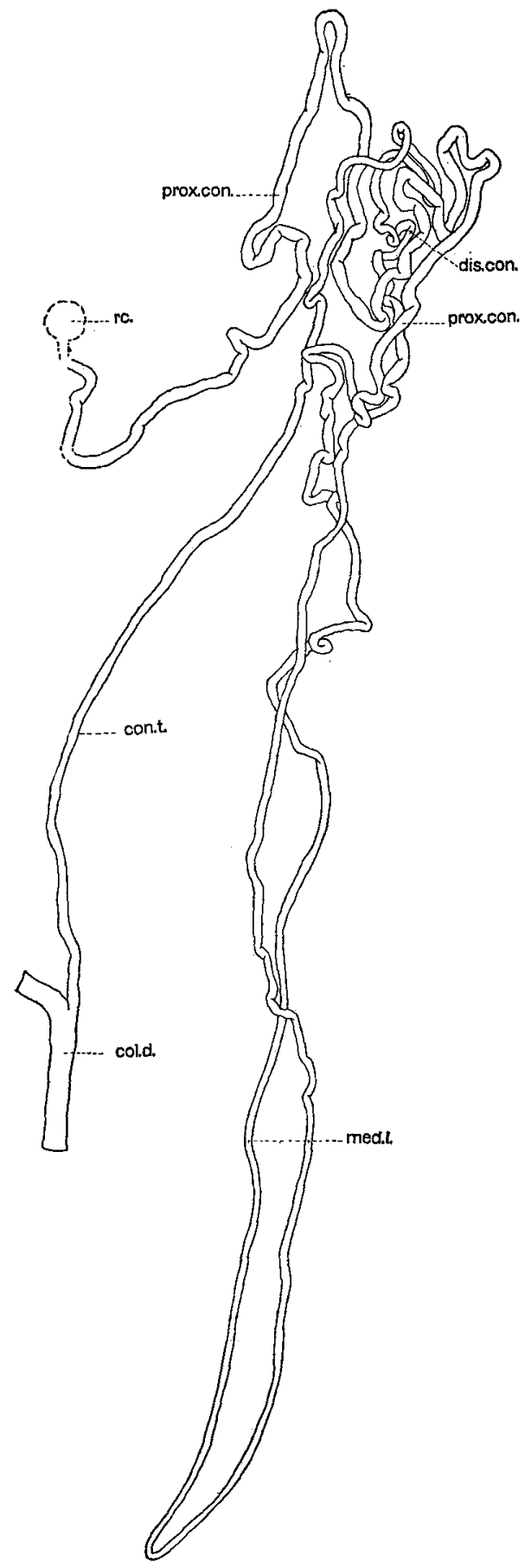



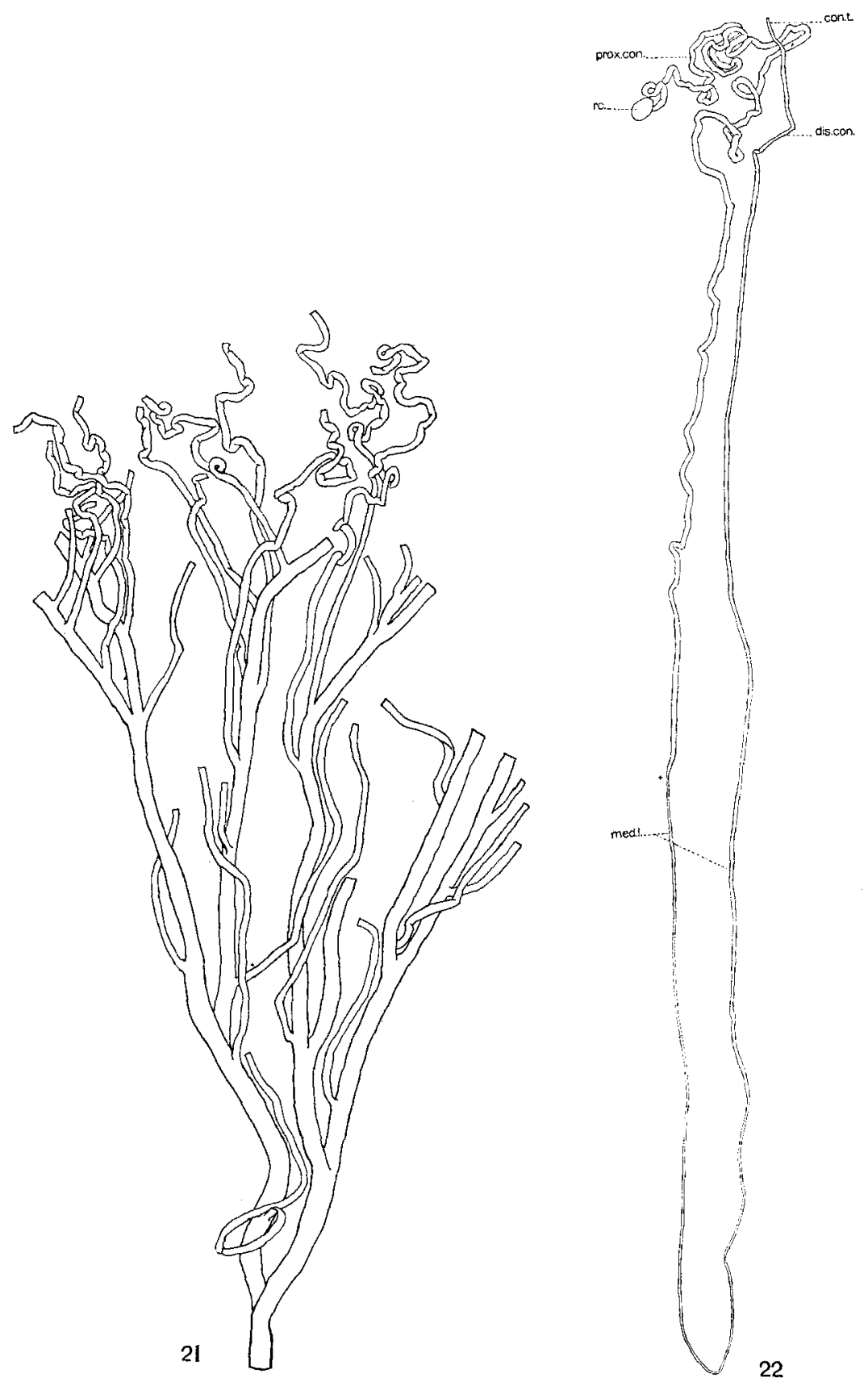
successful teased preparation of the duct system of the bird's kidney made by me. The preparation came from the central portion of a renal lobule and traces one of the main collecting ducts through its several branches to and including the end segments of renal tubules ending in this portion of the duct system. Many of the main branches of this duct are not traced to their termination in this figure, but extend to the peripheral and lateral portions of the renal lobule receiving the renal tubules which have been described as showing a reptilian type of renal tubule. It will be observed that the renal tubules of the bird end in the several divisions of the duct system, those ending deep in the medulla having long connecting or junctional tubules as shown in figures 19 and 20.

A study of the figure of the avian renal tubule as here presented may serve to show that in the birds kidney, there is found a transition, so far as concerns the form of the renal tubule, from the reptilian type of metanephric tubule to the mammalian type of the metanephric tubule. A study of the vascular supply, with the use of the modern corrosion methods is very desirable. Zarnik gives a good account of the blood supply of the reptilian kidney, I believe as far as concerns the terminal branches of the renal artery and their relation to the renal tubule of the mammalian kidney, my own account gives correctly the essentials. It is desirable, therefore, that the details of the blood supply of the avian kidney be equally carefully studied. It is hoped that opportunity will present itself to do this in this laboratory or that some other laboratory will undertake this investigation.

Fig. 21 Primary collecting duct with branches, teased from the center of a renal lobule of the bird, Gallus domestica. The tortuous tubules, upper part of figure, represent distal convoluted and junctional segments of renal tubules.

Fig. 22 Renal tubule of rabbit, isolated by teasing. $\times 20$. $r c$, renal corpuscle; prox.con., proximal convoluted segment; med.l., medullary loop, from $X$ to $X$ of this loop, the thin segment lined by squamous epithelium. dis.con., distal convoluted segment. The tubule ends just distal to distal convoluted portion. 


\section{METANEPHRIC TUBULES OF MAMMALS}

It is not my purpose to discuss here fully the renal tubules of the mammalian kidney. This has been done relatively recently by Karl Peter ${ }^{10}$ in his comprehensive monograph, by Inouye $^{10}$ in an addendum to the Peter monograph, by Zarnik in his report on the renal tubules of Echidna and by myself, my report being based on completely isolated renal tubules of the rabbits kidney. However, in order to make this series of renal tubules of vertebrates complete in this one article, there is here given in figure 22 , a new drawing of tubule $\mathrm{B}$, of plate $\mathrm{I}$, accompanying the contribution-"A method for isolating the renal tubules of mammalia" (Huber) ${ }^{2}$ reproduced here at a magnification of 20 diameters, one-half of the magnification used in reproducing the renal tubules of birds, and one-fourth of the magnification used in the reproduction of the renal tubules of the other vertebrates studied. From the text of the article mentioned it may be learned that the mammalian renal tubule here shown, and which may be taken as a type tubule, has a total length of $23 \mathrm{~mm}$. It presents a mammalian renal tubule of medium length. One, the renal corpuscle of which is situated at about the mid level of the cortex. In this tubule, the proximal convoluted portion with the medullary segment has a length of $9.4 \mathrm{~mm}$.; the thin portion of the medullary loop, a length of 6.7 $\mathrm{mm}$.; the thicker portion of the ascending limb of the medullary loop to the level of the renal corpuscle a length of $6.0 \mathrm{~mm}$; the distal convoluted segment a length of $0.9 \mathrm{~mm}$. The tubule was isolated completely and mounted in the position as drawn" to just beyond the distal convoluted portion. The connection or junctional segment is thus missing. This would add approxi-

${ }^{10}$ Peter, Karl. Untersuchung über Bau und Entwickelung der Niere. ('Karl Peter, Die Nierenkanälchen des Menschen und einiger Säugetiere. ${ }^{2}$, Michio Inouye, die Nierenkanälchen des Rindes und des Trümmlers. Gustav Fischer, Jena, 1909.

${ }^{11}$ In the figure as here given, the loop in the lower end of the medullary loop, as drawn in tubule B, plate 1, Anat. Rec., vol. 5, is eliminated. This was done by first drawing the lower end of the medullary loop as found in the preparation, then placing a string over the tracing then extending the string in the form of a simple loop, as given in figure 22 . 
mately $1 \mathrm{~mm}$. to the total length of this tubule. The epithelium characterizing the different segments of the mammalian renal tubule, I have discussed in the former publication as also the position of the different segments in the kidney substance and their relation to each other.

A careful investigation, with the use of appropriate maceration and teasing methods of the renal tubules of a number of mammals is still desirable. Peter has called attention to the difference in structure of the two arms of the medullary loop and of the loop itself in different mammals and in the same kidney for tubules of different lengths. This I have confirmed, but not in preparations showing renal tubules, completely isolated, so that the comparative and total length of the different segments of a given renal tubule could be given; which is much to be desired. Other parts of the renal tubules of mammals vary in detail of structure. In the guinea pig, for instance, the distal convoluted portion has a diameter which is approximately the same as that of the proximal convoluted portion, though it is much shorter, differing in this respect from that of the rabbit. The close relation existing between structure and function makes it desirable to be fully informed as to the details of structure of the different segments of the renal tubules.

It is hoped that this series of figures, brought together in limited space, presenting type forms of the renal tubules of the different classes of vertebrates, may not be without value to both students of morphology and functions. 